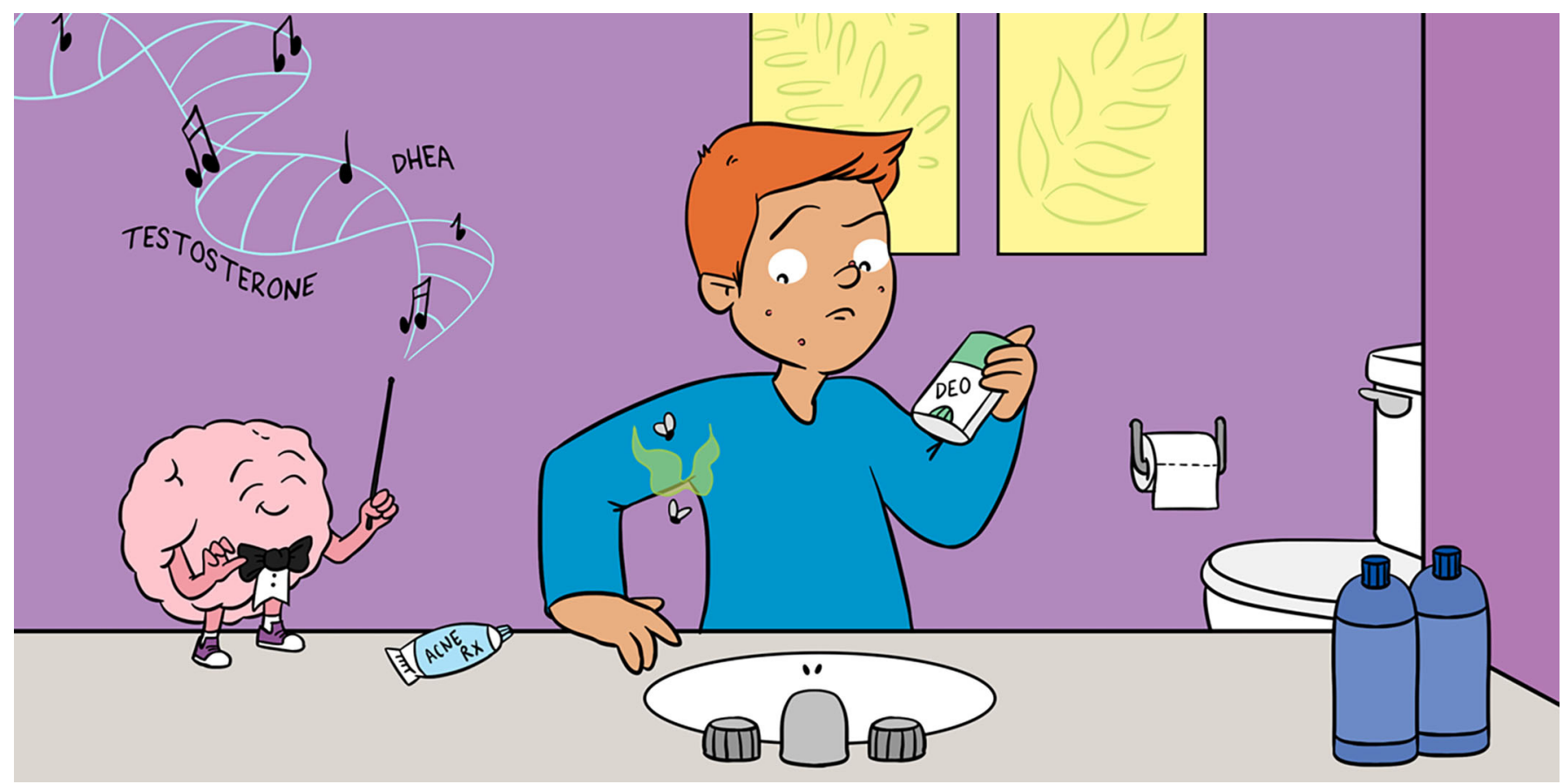

\title{
PUBERTY: YOUR BRAIN ON HORMONES
}

\section{Katherine E. Kabotyanski ${ }^{*}$ and Leah H. Somerville}

Center for Brain Science, Harvard University, Cambridge, MA, United States

YOUNG REVIEWER:

MARIA

AGE: 11
As humans grow from children into adults, they pass through a stage called adolescence. Adolescence is a time of major social, environmental, and biological change in a person's life. The start of puberty, which often happens around the teenage years, is an important period of human physical and emotional development. In addition to the more obvious bodily changes that happen during this time, an adolescent's brain also goes through changes that may not be as visible. These changes are directed by chemicals called hormones. Hormones help our bodies become taller, change shape, and even grow hair. Although hormones act on different parts of the body (like bones, muscles, or skin), several crucial hormones for puberty are actually made in the brain. Scientists are learning more about the ways hormones affect how the brain grows and changes, and in turn, the way that changes how you act and feel!

Wherever you are from, whether you are a boy or girl, from the moment you are born your body begins to change and continues to do so as you get older. This is a process called human development. We can think about human development as moving through several important stages in life, such as infancy (ages 0-2), childhood (ages 
Figure 1

There are around 50 different kinds of hormones in the human body. Some, like adrenaline and cortisol, help us react to stress and initiate the "fight-or-flight" response. Others, like melatonin, help set our biological clocks and tell us when to sleep or wake up. Many, such as thyroxin and insulin, help control metabolism. Others still, such as estrogen, testosterone, and growth hormone, are critical for changes that happen to our bodies as we develop during adolescence, like the growth of reproductive organs.

\section{ADOLESCENCE}

A period of physical and psychological development that includes the transition from childhood to adulthood.

\section{HORMONES}

Chemicals made in one part of the body (an endocrine gland) that then travel through the blood to tell other parts of the body what to do.

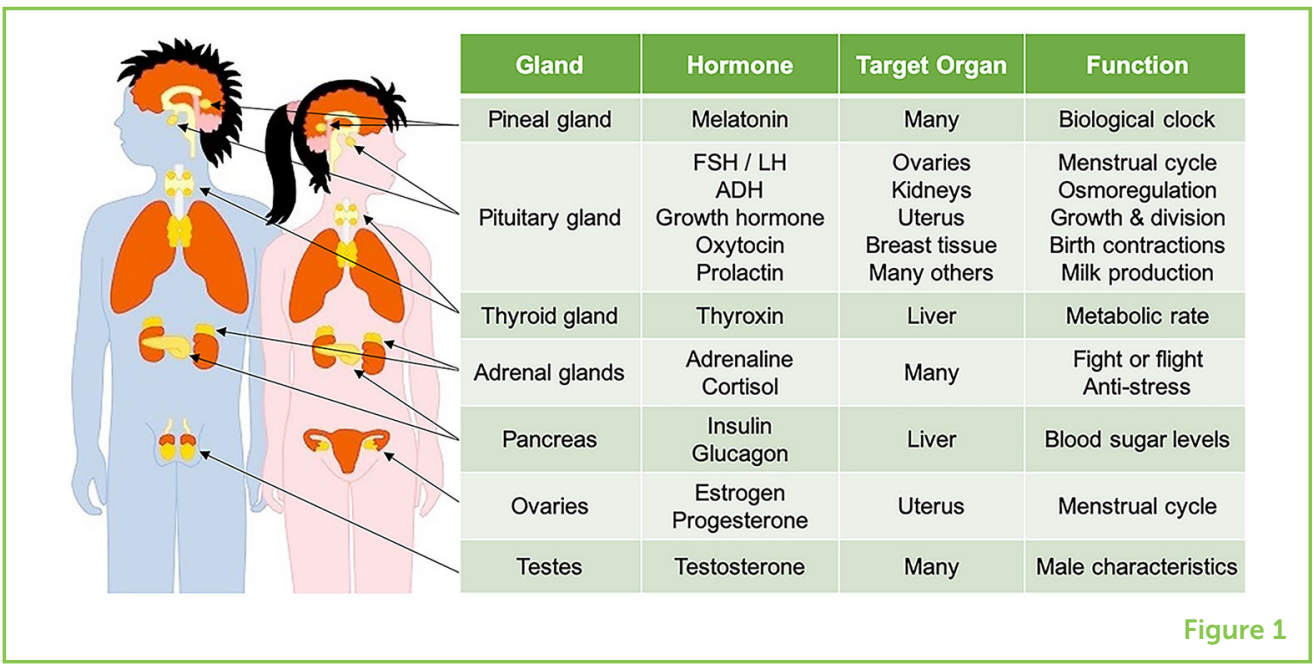

3-11), adolescence (ages 12-18), and young adulthood (ages 18-24). As you can imagine-and maybe have already experienced yourself-a lot changes from infancy to young adulthood! Understanding these changes and how they happen can help us better understand ourselves and those around us as we mature.

\section{HORMONES AND THE BODY}

How does the body know to grow? What happens on the inside that makes us change on the outside? If you think about any complex process, it usually requires an organized system to manage all the moving parts. When you listen to a symphony, for example, many different instruments must play the right notes at the right times to produce the beautiful music we hear. For all these separate elements to work together, a conductor tells each instrument what, when, and how to play.

In the body, our genes are like musical notes that are strung together to make each body's own unique song. When the appropriate time comes, special chemicals called hormones are like conductors that tell other parts of the body what to do. The many organ systems in the body are then like the instruments that carry out the conductor's commands and bring the entire process to life. During these intricate periods of transition, hormones serve as messengers that travel throughout the body and give orders to grow (or stop growing), change shape and size, or make more (or less) of something the body needs (Figure 1) [1].

\section{WHAT HAPPENS DURING PUBERTY?}

Puberty is the name we give to a series of hormone-driven changes that happen in our bodies right before and during adolescence, the 


\section{Figure 2}

Early in puberty, the adrenal glands (located on top of the kidneys) produce hormones called androgens, like DHEA (green). You may see the earliest signs of puberty in this phase, like pubic hair, body odor, oily skin, and acne. Then, two small brain regions, called the hypothalamus and pituitary gland (pink), send messages to the reproductive organs, telling them to make sex steroids like testosterone, estrogen, and progesterone (blue). These hormones can shape the brain's structure and function throughout development.

\section{ANDROGENS}

Hormones made by adrenal glands (in males and females), testes (in males only), and ovaries (in females only) that regulate growth of hair, bones, and the male reproductive system.

\section{SEXUAL}

\section{DIMORPHISM}

A biological feature that is different in males and females of the same species, such as the lion's mane (only in males) or the kangaroo pouch (only in females).

\section{SEX STEROIDS}

A group of hormones made from cholesterol that control the differences between male and female sexual development during puberty.

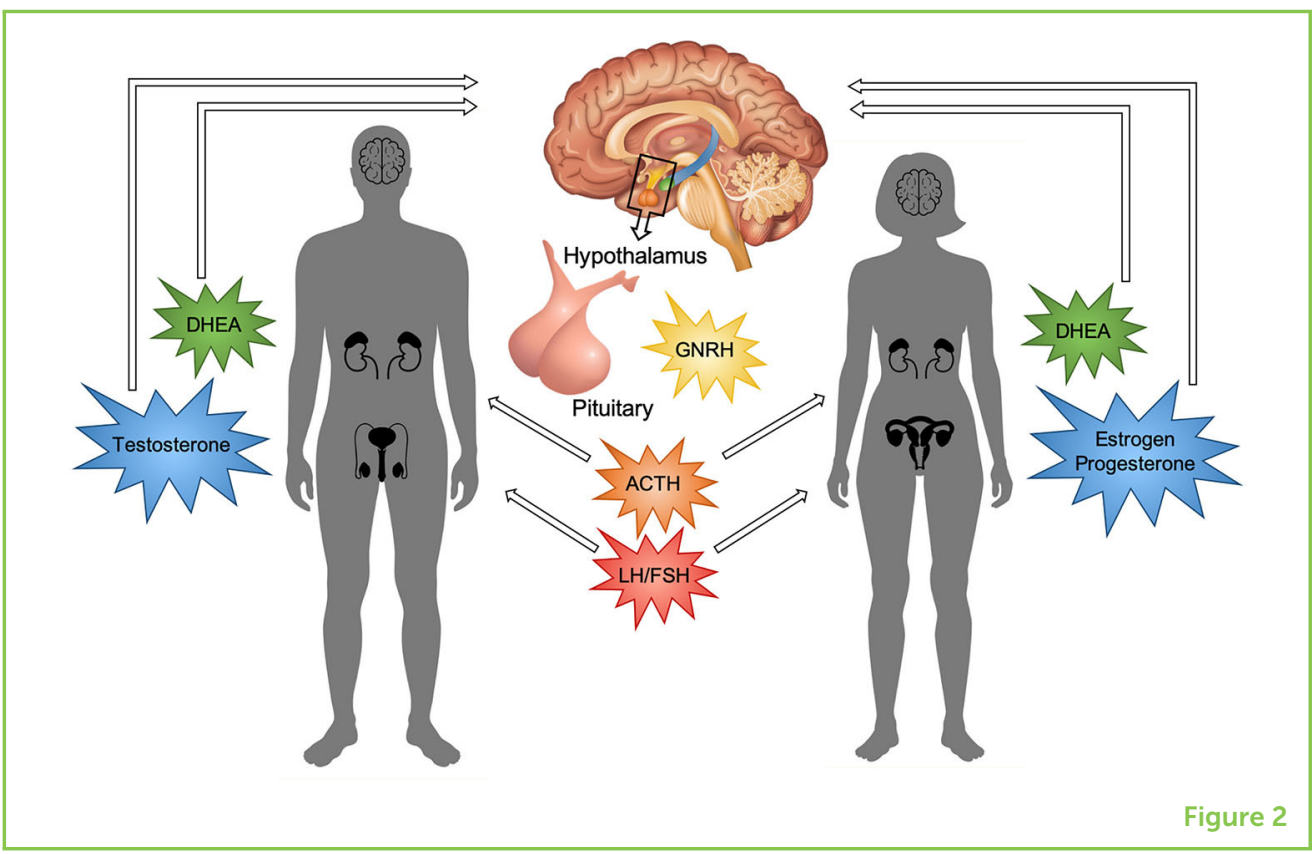

time when we grow from children into adults (Figure 2). The shape, size, and composition of our bodies change as we progress toward sexual maturity, which is the ability of an organism to reproduce. Our moods and behaviors change as a result of puberty as well. The same hormones that cause changes in our bodies also help shape the structure and organization of our brains. Through puberty, our brains strengthen and fine-tune the connections that allow for mature ways of thinking, feeling, and behaving [2].

Androgens are a group of hormones often associated with male characteristics, but they are also crucial for proper development of females. While males experience a large surge in the androgen testosterone during puberty, testosterone also increases in females, but less than in males. As a result, brain circuits are organized in sex-specific ways, making the brains of women and men slightly different. This includes differences in the growth, survival, and type of cells in several brain regions. These subtle differences, called sexual dimorphisms, prepare our brains for the unique biological demands of both sexes [3].

Another group of hormones called sex steroids are produced by ovaries in females and testis in males, and they stimulate the development of secondary sex characteristics. For girls, this includes wider hips, larger breasts, and the start of menstruation. For boys, this involves increased muscle mass, a deeper voice, and growth of facial hair. A rapid increase in height called a growth spurt usually accompanies puberty in boys and girls. Steroid hormones also activate brain circuits involved in sexual behaviors, which is why adolescents experience increased interest in sex. 
SECONDARY SEX CHARACTERISTICS

Changes in appearance caused by increasing sex hormones during puberty that are different in males and females and symbolize the completion of sexual development.

\section{NEURONS}

A type of cell in the brain and nervous system that carries information using electrical signals.

\section{HOW CAN WE STUDY THE EFFECTS OF PUBERTY ON THE BRAIN?}

On average, puberty occurs between ages 10 and 14 in girls and between ages 12 and 16 in boys. There is a lot of variation in the timing of puberty across individuals. Scientists have found that the onset, duration, and tempo of puberty can be influenced by factors like a person's cultural background, education level, body composition, and genes. Interestingly, the average age that puberty starts has decreased over generations. The ability to accurately and reliably measure the changes that happen during the early phases of puberty is an important step in understanding how puberty affects the brain [4].

One way that scientists can study the effects of hormones on the brain is by studying animals like rats. Using animals, we can better control environmental factors like diet, and we can perform experiments that would be impossible to perform on humans. We can remove parts of the body where hormones are produced (like the testes or ovaries) and study how development proceeds without these hormones. We can use chemicals to trigger puberty and trace the growth of specific neurons in the brain. And because rats have shorter lifespans than humans, we can study adolescence in the span of weeks rather than years. Animals allow us to learn about biological mechanisms like puberty at a level of detail not possible any other way.

Still, there are major differences between humans and other species, so we cannot assume that what happens in rats is exactly what happens in people. We cannot modify a person's hormones for research, because it could have a long-lasting impact on the person. Instead, to study humans, researchers measure things that are already naturally occurring in the body, like the amount of testosterone in the blood or the age at the first menstrual cycle. Scientists can then test whether these bodily changes are linked with other body measurements, such as brain volume. These links cannot tell us whether one thing causes another, only that they are related somehow.

\section{PUBERTAL HORMONES CHANGE BRAIN STRUCTURE AND FUNCTION}

Puberty is a dynamic transition period that prepares us for the adult world. Yet, even as adults, life is constantly in flux and our brains need ways of adapting to these ongoing changes. The same hormones that help shape the brain and body during puberty are actually at play throughout the entire lifespan! Even before birth, testosterone and estrogen are involved in early brain development, helping to create new neurons and guide them as they form the brain's structure. During puberty, these hormones then act to permanently change 
Figure 3

Different parts of the brain change in response to different hormones. Androgen hormones like testosterone and DHEA, as well as estrogen hormones like estradiol, are especially important for the proper development of parts of the brain involved in learning and memory, sexual behaviors, and emotion processing. Using animal models together with studies of healthy humans as well as those with hormonal disorders, scientists are starting to get a better picture of how the pubertal hormones change the structure and the function of the brain.

\section{MYELINATION}

A kind of insulation that covers neurons in a substance called myelin so that they can quickly carry information to other neurons that are far away.

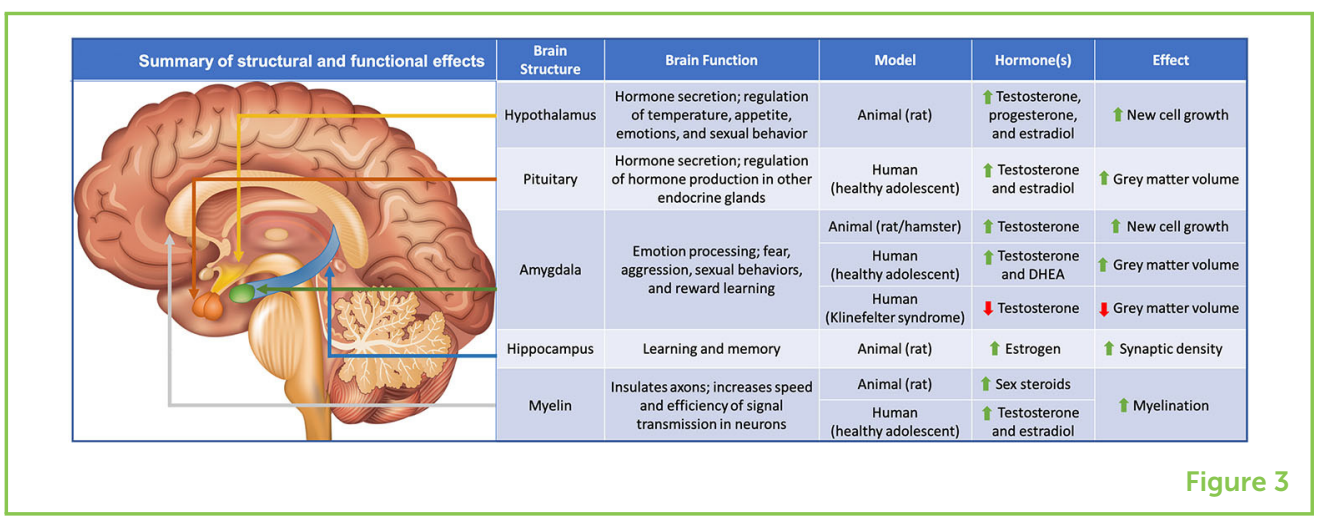

the organization and structure of the brain into its mature form (Figure 3).

There are several ways that brain structure can be altered. One is neuron growth or death, which changes the overall size of brain regions. In animals and healthy humans, pubertal hormones are necessary for proper growth of brain structures like the hypothalamus, pituitary gland, and amygdala. Since the hypothalamus and pituitary gland are crucial for life-long hormone regulation, improper growth of these brain regions during puberty can lead to long-term health consequences, such as disorders of sleep or metabolism. Klinefelter syndrome, which is a genetic disorder caused by an extra $X$ chromosome, leads to a shortage of testosterone and a significantly decreased amygdala volume in adolescence. These hormonal and brain structure changes may contribute to the social and emotional problems these individuals face, including social anxiety and difficulty expressing feelings.

Another way to alter brain structure is by changing the number of connections each neuron makes with other neurons, which changes the overall complexity of brain circuits. For example, the hippocampus has a high number of hormone receptors for the hormone estrogen, and estrogen has been shown to increase the number of connections between neurons in rats. An increased number of neuronal connections in the hippocampus may have implications for the improvements in learning and memory often seen in adolescence. In animals and humans, sex steroids play a critical role in myelination, a process that insulates the brain's neurons so that the electrical signals are more efficient. The fact that myelination happens during puberty tells us that efficient communication between brain regions, helping us to process information quickly, is a necessary part of the brain's maturation process [5].

\section{PUBERTY IS AN EXCITING CHALLENGE!}

Ultimately, what we currently know about how pubertal hormones affect the brain is only the tip of the iceberg. Studying this topic is a bit 
like trying to understand how a symphony is played without being able to see the orchestra. We hear the music-meaning we see children pass through puberty and develop into adults-but we do not quite understand all the details involved. We know that there are notes (our genes), a conductor (our hormones), and many different instruments (our organ systems), but we do not know who the musicians are, where they are sitting, or which instruments they are playing and when. We do not fully understand who the composers are, because we have yet to learn exactly how DNA encodes the genetic instructions for puberty. And like any piece of music, there are subtle variations in rhythm and tempo each time it is played. All these intricacies make going to the symphony exciting, and they are also what makes puberty a fascinating topic for scientists to explore. Just as experienced concertgoers can learn to pick out the instruments being played, scientists can learn to interpret the body's cues and crack the code of complex biological mechanisms. We hope young scientists, like you, will join us in this challenge!

\section{REFERENCES}

1. Chrousos, G. P. 2007. Organization and Integration of the endocrine system. Sleep Med. Clin. 2:125-45. doi: 10.1016/j.jsmc.2007.04.004

2. Sisk, C. L., and Zehr, J. L. 2005. Pubertal hormones organize the adolescent brain and behavior. Front. Neuroendocrinol. 26:163-74. doi: 10.1016/j.yfrne.2005. 10.003

3. Juraska, J. M., Sisk, C. L., and DonCarlos, L. L. 2013. Sexual differentiation of the adolescent rodent brain: hormonal influences and developmental mechanisms. Horm. Behav. 64:203-10. doi: 10.1016/j.yhbeh.2013.05.010

4. Mendle, J., Beltz, A. M., Carter, R., and Dorn, L. D. 2019. Understanding puberty and its measurement: ideas for research in a new generation. J. Res. Adolesc. 29:82-95. doi: 10.1111/jora.12371

5. Goddings, A. L., Beltz, A., Peper, J. S., Crone, E. A., and Braams, B. R. 2019. Understanding the role of puberty in structural and functional development of the adolescent brain. J. Res. Adolesc. 29:32-53. doi: 10.1111/jora.12408

SUBMITTED: 21 April 2020; ACCEPTED: 22 December 2020; PUBLISHED ONLINE: 02 February 2021.

EDITED BY: Daniel W. Wesson, University of Florida, United States

CITATION: Kabotyanski KE and Somerville LH (2021) Puberty: Your Brain on Hormones. Front. Young Minds 8:554380. doi: 10.3389/frym.2020.554380

CONFLICT OF INTEREST: The authors declare that the research was conducted in the absence of any commercial or financial relationships that could be construed as a potential conflict of interest.

COPYRIGHT () 2021 Kabotyanski and Somerville. This is an open-access article distributed under the terms of the Creative Commons Attribution License (CC BY). 


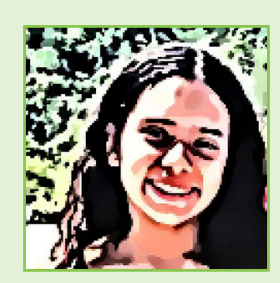

The use, distribution or reproduction in other forums is permitted, provided the original author(s) and the copyright owner(s) are credited and that the original publication in this journal is cited, in accordance with accepted academic practice. No use, distribution or reproduction is permitted which does not comply with these terms.

\section{YOUNG REVIEWER}

\section{MARIA, AGE: 11}

My name is Maria. I am 11 years old. I love neuroscience. My favorite subjects are Science and Math. In my free time, I really love reading, dancing, and doing research. I want to know more about the brain so I can help people when I grow up.

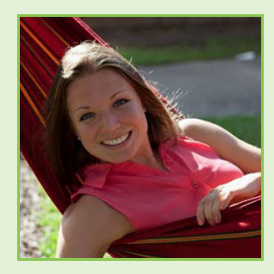

\section{AUTHORS}

\section{KATHERINE E. KABOTYANSKI}

I am a researcher at Harvard University. I work on the Human Connectome Project in Development, trying to understand the connections in the brain and how they change over time as children become adults. I am fascinated by human development and the brain, particularly how structural and functional brain changes during early childhood and adolescence impact long-term health and may underlie vulnerability for negative health outcomes. I am pursuing a career as a physician-scientist in hopes of bridging the gap between scientific discoveries and medical care. *kkabotyanski@g.harvard.edu

\section{LEAH H. SOMERVILLE}

I am a Professor of Psychology at Harvard University and the Director of the Affective Neuroscience and Development Laboratory. My research aims to understand how brain development through adolescence shapes changes in cognitive, motivational, social, and emotional behavior. I have always been fascinated by adolescence and love coming up with creative experiments to solve complex scientific puzzles. My hope is that this work will help scientists understand the mechanisms that underlie risk for mental illness in adolescence. 